\title{
EFFICIENCY OF WATER FILTERING PROCESS DEPENDING ON THE FILTER LAYER POROSITY AND FLOW - A MATHEMATICAL MODEL
}

\author{
OANA TIRTOACA (IRIMIA) ${ }^{* 1}$, VALENTIN NEDEFF ${ }^{1,2}$, MIRELA PANAINTE- \\ LEHADUS $^{1}$, CLAUDIA TOMOZEI ${ }^{1}$ \\ I "Vasile Alecsandri" University of Bacau, Calea Marasesti 157, Bacau, 600115, Romania \\ ${ }^{2}$ Academy of Agricultural and Forestry Sciences "Gheorghe Ionescu Sisesti", \\ B-dul. Marasti nr. 61, Sector 1, Bucuresti, Romania
}

\begin{abstract}
Mathematical modeling represents a challenge for any researcher or engineers that working in the field of applied sciences. The experimental approach to the water filtering process allowed achieving and verification a three-dimensional mathematical model, depending on the intake flow of the filter, the porosity of the filter layer and the nature of the filter layer. The mathematical model was developed and verified using the software Table Curve 3D. It was found that the mathematical model proposed offers a viable and robust method for determining the mechanical filtration efficiency of water.
\end{abstract}

Keywords: potable water, mathematical modeling, water treatment, filtration

\section{INTRODUCTION}

The mathematical modeling represents an important part of research work in the development of science and engineering fields. The competitive edge of this research work requires a connection between idea and prototype, on the one hand, and simulation and mathematical modeling, on the other hand, which allows a rapid understanding of quantitative and qualitative aspects of the study both scientific and engineering point of view $[1,2]$.

In a broader definition, a mathematical model is an abstract mathematical representation (by mathematical relations) of an object (a piece, a product, a car, an organization etc.), a process (specific manufacturing or business) or a concept, this mathematical representation being used for analysis and planning [2].

The mathematical modeling studied in natural sciences, in engineering disciplines or in social sciences is an area of great interest and has a broad impact in the most varied fields. For example, in environmental engineering the mathematical modeling is developed for all environmental factors - water, air or soil [1, 3].

In soil science the mathematical models describing, in particular, the migration of pollutants in soil. The mathematical modeling is also studying for risk assessment of contamination produced by certain pollutants, for design of remediation technologies for soil or for descriptions or soil erosion etc. [1]. As regards the environmental factor "air" are performed mathematical models that describe the dynamics and / or dispersion of pollutants in the atmosphere. Can be made at the same time, models which help to determine the concentration of pollutants generated by certain industries, thus could able to predict their behavior into the atmosphere etc. [1].

\footnotetext{
*Corresponding author, email: oana.tartoaca@ub.ro

(C) 2016 Alma Mater Publishing House
} 
Regarding the environmental factor "water", the mathematical models describe, as in the case of the environmental factor "soil", the movement and the behavior of pollutants in various bodies of water. The mathematical modeling allows, also, to quantify the impact of human activity on the water or to designate vulnerable areas. It can track, so, the evolution in time and space of the pollutant concentration. In the water treatment domain can be illustrates a series of mathematical models presented by different authors [4-7].

In paper "Modeling of suspension fouling in nanofiltration" were carried out researches regarding the nanofiltration process of water. Thus, have been performed experimental studies relating to resistance of membranes as well as to dissolving of the inorganic solid particles deposited in precipitated layer in a cross-flow system. Following the completion of experimental studies was performed a mathematical model which can predict the performance of the water treatment process by nanofiltration. A comparison between experimental and mathematical models offered an average error of $3.25 \%$. The authors concluded that the two models help to optimize the membrane filtration and their operating conditions [5].

The work performed by Wang D. et al. presents the feasibility of the water disinfection process with UV radiations in combination with chlorine, in controlled laboratory conditions. In order to establish the efficiency of water treatment process with UV in combination with chlorine, comparative experimental studies have been conducted between this process (UV radiations in combination with chlorine) and conventional UV disinfection. The pollutant taken into account in this study was the trichloroethylene. Experimental studies have shown that the efficiency of water treatment process with UV radiations is increased when chlorine is used as oxidizing agent. Mathematical modeling of experimental research performed using MATLAB software showed good agreement with the experimental data [6].

In research conducted by Yahyapour S. et al. are presented experimental studies on removing of suspended solids and turbidity from drinking water using vegetation. The experiments were held in an open vegetated channel being considered as variable parameters flow velocity at the entrance, density of vegetation and the length of vegetation zone. The research has shown that the vegetation plays an important role in transport and settling of the suspended solids in the raw water. It argued, also, that the studied parameters which have been varied are very important and have a significant influence in the removing process of suspended solids and turbidity from drinking water. Also for these studies, it was developed a mathematical model that certify that mathematical model developed is accurate and there is an agreement closely with estimated and experimental values [7].

Similar to the above researches, this paper aims to identify a mathematical model with which to streamline the water filtering process. The mathematical model is based on a series of experimental values obtained under laboratory conditions. The variable parameters taken into consideration for conducting the experiments are represented by the nature of the filtering material, the porosity of the filter layer which is related to the shape of the particle which forms the filter layer and the intake flow of the filter, while the other filter parameters which influence the process are considered constant. The mathematical model was validated by comparing experimental data obtained under laboratory conditions to those offered by mathematical modeling software, TableCurve 3D.

\section{EXPERIMENTAL SETUP}

The experimental researches been conducted in the laboratory of Environmental Engineering, Engineering Faculty from "Vasile Alecsandri" University of Bacau, in a ,test-tube filter". The schematic representation of the „test-tube filter" is shown in Figure 1 [8 - 11]. It is the main component elements the intake container with raw water, the filtration column and tank for collecting the treated water. The filtration plant has also a device that allows the adjusting the feed rate of raw water filter.

For conducting the experiments, the following parameters were varied: the nature of the filtering material (quartz sand, perlite and anthracite), the intake flow of the filter $(2 \mathrm{~mL} / \mathrm{s}, 1.5 \mathrm{~mL} / \mathrm{s}, 1 \mathrm{~mL} / \mathrm{s}, 0.8 \mathrm{~mL} / \mathrm{s}, 0.5 \mathrm{~mL} / \mathrm{s})$ and the porosity of the filter layer which is related to the shape of the particle which forms the filter layer. In Table 1 it is presented the value of porosity for each filtering material according to the particle shape which they form [12].

The value of the filtration process according to the nature of the filtering material, its porosity and the intake flow of the filter is presented in Table 2. 
The experimental data obtained in situ in "test-tube filter", shown in Table 2, were transposed into mathematical models using a three-dimensional mathematical modeling software, Table Curve 3D [13].

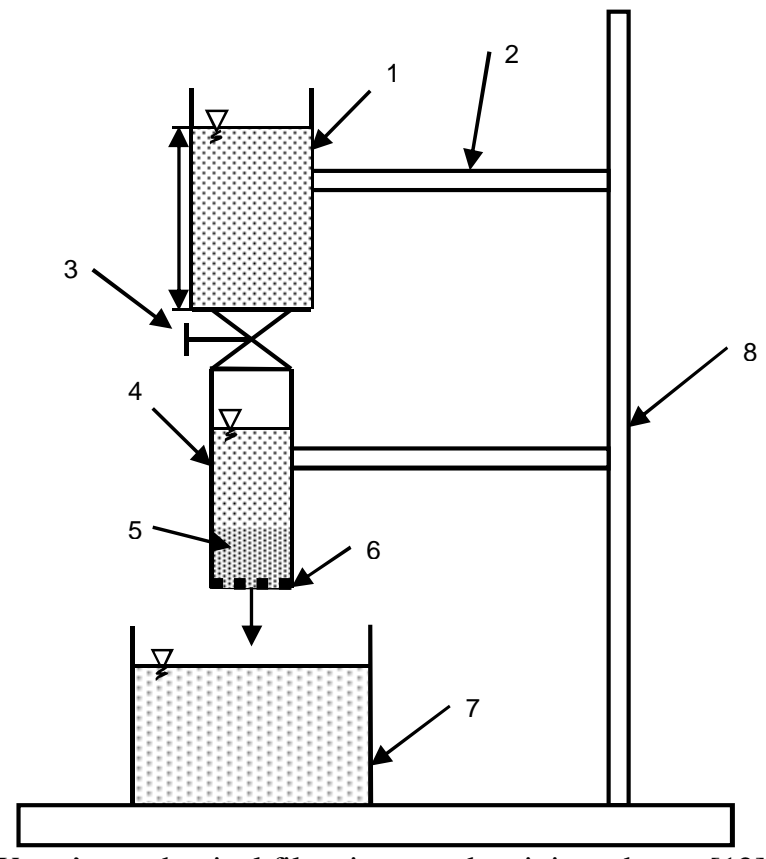

Fig. 1. Water's mechanical filtration stand activity scheme [12]:

1 -raw water tank; 2, 8 - metal frame; 3 - tap valve; 4 - filtration column; 5 - granular filter material; 6 - sieve; 7 - collecting container for filtrate water.

Table 1. The value of porosity of filtering layer depending on particle shape [12].

\begin{tabular}{|l|c|l|c|l|c|}
\hline \multicolumn{2}{|c|}{ Quartz sand } & \multicolumn{2}{c|}{ Perlite } & \multicolumn{2}{c|}{ Anthracite } \\
\hline \multicolumn{1}{|c|}{ Particle shape } & Porosity & \multicolumn{1}{c|}{ Particle shape } & Porosity & \multicolumn{1}{c|}{ Particle shape } & Porosity \\
\hline compact & 37.66 & compact & 41.25 & compact & 40.02 \\
\hline compact platy & 40.78 & compact platy & 42.54 & compact platy & 41.82 \\
\hline compact blade & 40.27 & compact blade & 41.82 & compact blade & 41.25 \\
\hline compact elongate & 40.17 & compact elongate & 41.56 & compact elongate & 42.83 \\
\hline platy & 42.76 & platy & 43.46 & platy & 43.85 \\
\hline bladed & 41.37 & bladed & 44.21 & bladed & 43.23 \\
\hline elongate & 43.07 & elongate & 46.37 & elongate & 44.59 \\
\hline
\end{tabular}

Table 2. The value of the filtration process according to the nature of the filtering material, the porosity of the filter layer and the intake flow of the filter [12].

\begin{tabular}{|c|c|c|c|c|c|c|c|c|}
\hline \multicolumn{3}{|c|}{ Quartz sand } & \multicolumn{3}{c|}{ Perlite } & \multicolumn{3}{c|}{ Anthracite } \\
\hline $\mathrm{Q}$ & $\mathrm{P}$ & Ef. & $\mathrm{Q}$ & $\mathrm{P}$ & $\mathrm{Ef}$ & $\mathrm{Q}$ & $\mathrm{P}$ & Ef. \\
\hline 2 & 37.66 & 45 & 2 & 41.25 & 23.33 & 2 & 40.02 & 26.66 \\
\hline 1.5 & 37.66 & 50 & 1.5 & 41.25 & 25 & 1.5 & 40.02 & 23.33 \\
\hline 1 & 37.66 & 51.66 & 1 & 41.25 & 28.33 & 1 & 40.02 & 25 \\
\hline 0.8 & 37.66 & 55 & 0.8 & 41.25 & 33.33 & 0.8 & 40.02 & 28.33 \\
\hline 0.5 & 37.66 & 63.33 & 0.5 & 41.25 & 36.66 & 0.5 & 40.02 & 33.33 \\
\hline 2 & 40.78 & 31.66 & 2 & 42.54 & 13.33 & 2 & 41.82 & 36.66 \\
\hline 1.5 & 40.78 & 33.33 & 1.5 & 42.54 & 18.33 & 1.5 & 41.82 & 13.33 \\
\hline 1 & 40.78 & 40 & 1 & 42.54 & 23.33 & 1 & 41.82 & 18.33 \\
\hline 0.8 & 40.78 & 46.66 & 0.8 & 42.54 & 30 & 0.8 & 41.82 & 23.33 \\
\hline 0.5 & 40.78 & 56.66 & 0.5 & 42.54 & 33.33 & 0.5 & 41.82 & 30 \\
\hline 2 & 40.27 & 35 & 2 & 41.82 & 15 & 2 & 41.25 & 33.33 \\
\hline 1.5 & 40.27 & 40 & 1.5 & 41.82 & 20 & 1.5 & 41.25 & 15 \\
\hline 1 & 40.27 & 48.33 & 1 & 41.82 & 26.66 & 1 & 41.25 & 20 \\
\hline 0.8 & 40.27 & 53.33 & 0.8 & 41.82 & 28.33 & 0.8 & 41.25 & 26.66 \\
\hline
\end{tabular}




\begin{tabular}{|c|c|c|c|c|c|c|c|c|}
\hline 0.5 & 40.27 & 58.33 & 0.5 & 41.82 & 31.66 & 0.5 & 41.25 & 28.33 \\
\hline 2 & 40.17 & 40 & 2 & 41.56 & 20 & 2 & 42.83 & 31.66 \\
\hline 1.5 & 40.17 & 46.66 & 1.5 & 41.56 & 21.66 & 1.5 & 42.83 & 20 \\
\hline 1 & 40.17 & 50 & 1 & 41.56 & 26.66 & 1 & 42.83 & 21.66 \\
\hline 0.8 & 40.17 & 51.66 & 0.8 & 41.56 & 28.33 & 0.8 & 42.83 & 26.66 \\
\hline 0.5 & 40.17 & 58.33 & 0.5 & 41.56 & 33.33 & 0.5 & 42.83 & 28.33 \\
\hline 2 & 42.76 & 30 & 2 & 43.46 & 10 & 2 & 43.85 & 33.33 \\
\hline 1.5 & 42.76 & 31.66 & 1.5 & 43.46 & 15 & 1.5 & 43.85 & 10 \\
\hline 1 & 42.76 & 40 & 1 & 43.46 & 20 & 1 & 43.85 & 15 \\
\hline 0.8 & 42.76 & 43.33 & 0.8 & 43.46 & 21.66 & 0.8 & 43.85 & 20 \\
\hline 0.5 & 42.76 & 50 & 0.5 & 43.46 & 25 & 0.5 & 43.85 & 21.66 \\
\hline 2 & 41.37 & 33.33 & 2 & 44.21 & 8.33 & 2 & 43.23 & 25 \\
\hline 1.5 & 41.37 & 38.33 & 1.5 & 44.21 & 10 & 1.5 & 43.23 & 8.33 \\
\hline 1 & 41.37 & 45 & 1 & 44.21 & 15 & 1 & 43.23 & 10 \\
\hline 0.8 & 41.37 & 48.33 & 0.8 & 44.21 & 20 & 0.8 & 43.23 & 15 \\
\hline 0.5 & 41.37 & 51.66 & 0.5 & 44.21 & 23.33 & 0.5 & 43.23 & 20 \\
\hline 2 & 43.07 & 26.66 & 2 & 46.37 & 6.66 & 2 & 44.59 & 23.33 \\
\hline 1.5 & 43.07 & 35 & 1.5 & 46.37 & 11.66 & 1.5 & 44.59 & 6.66 \\
\hline 1 & 43.07 & 40 & 1 & 46.37 & 20 & 1 & 44.59 & 11.66 \\
\hline 0.8 & 43.07 & 46.66 & 0.8 & 46.37 & 23.33 & 0.8 & 44.59 & 20 \\
\hline 0.5 & 43.07 & 48.33 & 0.5 & 46.37 & 25 & 0.5 & 44.59 & 23.33 \\
\hline
\end{tabular}

The software Table Curve 3D gives researchers (bur not only to the researchers) the opportunity to identify an ideal mathematical model based on experimental data obtained in advance. The program offers a wide range of linear and nonlinear equations, offering the possibility to a graphical adjustment of variables for identify an ideal model [12].

\section{THE MATHEMATICAL MODEL}

\subsection{The elaboration of mathematical model}

The elaboration of mathematical model it was performed using the program for generation linear and nonlinear equations, Table Curve 3D. The values obtained experimentally were transposed in an Excel document, after which they were imported in Table Curve 3D software. Have been generated automatically 411 equations which describes the filtration efficiency using quartz sand as the filter material, 311 equations which describes the filtration efficiency using as a filter material anthracite and 311 equations that describe the efficiency of the filtration process using perlite as filter material $[12,13]$.

To identify the common equation that characterizes the mathematical model has been submitted for the analysis 1033 equations, automatically generated by the software. The common equation identified has the form:

$$
\begin{aligned}
z= & a+b \cdot \ln x+c \cdot y+d \cdot(\ln x)^{2}+e \cdot y^{2}+f \cdot y \cdot \ln x+g \cdot(\ln x)^{3}+h \cdot y^{3}+ \\
& +i \cdot y^{2} \cdot \ln x+j \cdot y \cdot(\ln x)^{2}
\end{aligned}
$$

where $[12,13]: \mathrm{x}$ represent the intake flow with raw water; $\mathrm{y}-$ the porosity of the filter layer; $\mathrm{z}-$ the efficiency of the filter; and $a, b, c . . . . f-$ the value of parameters which are obtained from 3D curve fitting software. The values of these parameters are shown in Table 3.

The correlation coefficients corresponding to this equation are: $r^{2}=0.94$ for the study of the filtration efficiency using quartz sand as filter material as, $\mathrm{r}^{2}=0.96$ in the case of perlite and $\mathrm{r}^{2}=0.82$ for anthracite.

Three-dimensional surfaces generated using TableCurve 3D software, which characterize the equation presented above, can be found in Figures 2, 3 and 4. These response surfaces describe the efficiency of the filtration process based on the parameters studied (the porosity of the filter layer, the nature of the filter layer and the intake flow with raw water) [12]. 
Table 3. The values of the equation constants that describe the mathematical model corresponding to the three type of filter materials accomplished in the "test-tube filter ", depending on the porosity of the filter layer and the intake flow of the filter [12].

\begin{tabular}{|c|c|c|c|}
\hline \multirow{2}{*}{$\begin{array}{c}\text { The constants of } \\
\text { equation }\end{array}$} & \multicolumn{3}{|c|}{ The nature of filter layer } \\
\cline { 2 - 4 } & Quartz sand & Perlite & Anthracite \\
\hline $\mathrm{a}$ & -1339110.3 & -862777.123 & -262947.84 \\
\hline $\mathrm{b}$ & 1085445.5 & 691393.7683 & 217360.7012 \\
\hline $\mathrm{c}$ & 3997.859598 & 287.0380574 & -24796.2698 \\
\hline $\mathrm{d}$ & -293198.393 & -184619.461 & -59824.5557 \\
\hline $\mathrm{e}$ & 122.6368748 & 118.8156149 & -415.426079 \\
\hline $\mathrm{f}$ & -2233.29786 & -215.090553 & 13470.67952 \\
\hline $\mathrm{g}$ & 26393.72169 & 16427.55725 & 5483.092881 \\
\hline $\mathrm{h}$ & -2.60960877 & 2.833928041 & 22.99566289 \\
\hline $\mathrm{i}$ & -28.9976536 & -33.5815112 & 94.44062988 \\
\hline $\mathrm{j}$ & 308.726079 & 36.40947974 & -1826.26351 \\
\hline
\end{tabular}

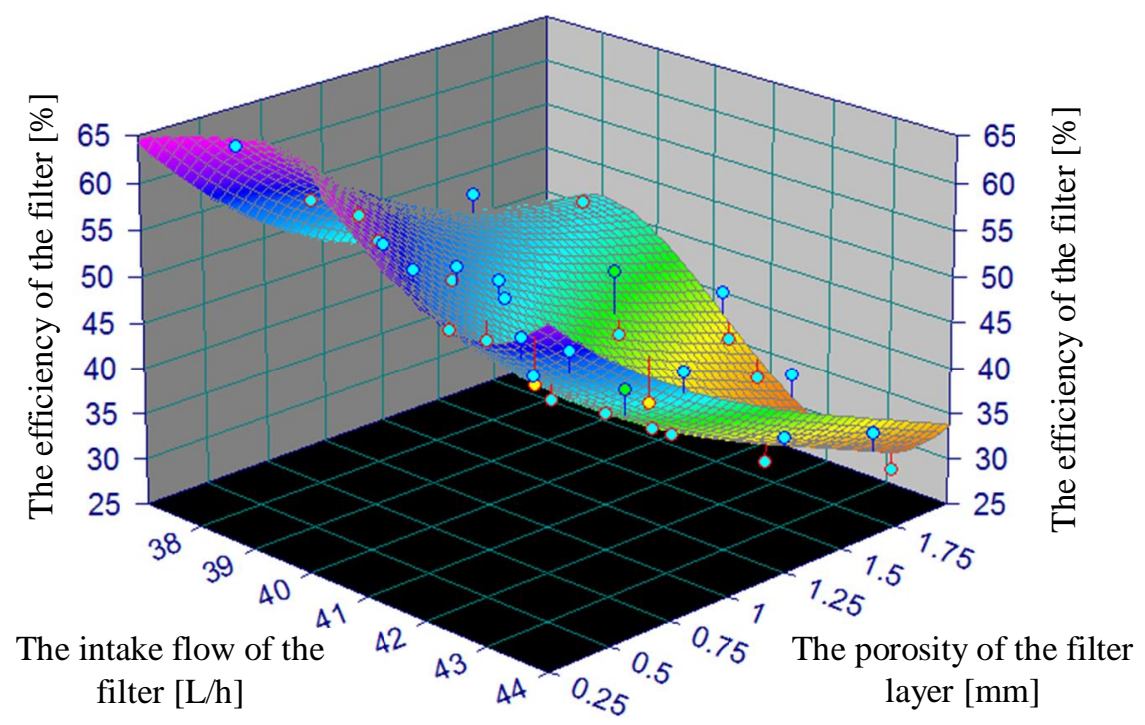

Fig. 2. Tridimensional representations of the filtering process efficiency for the filter with quartz sand [12].

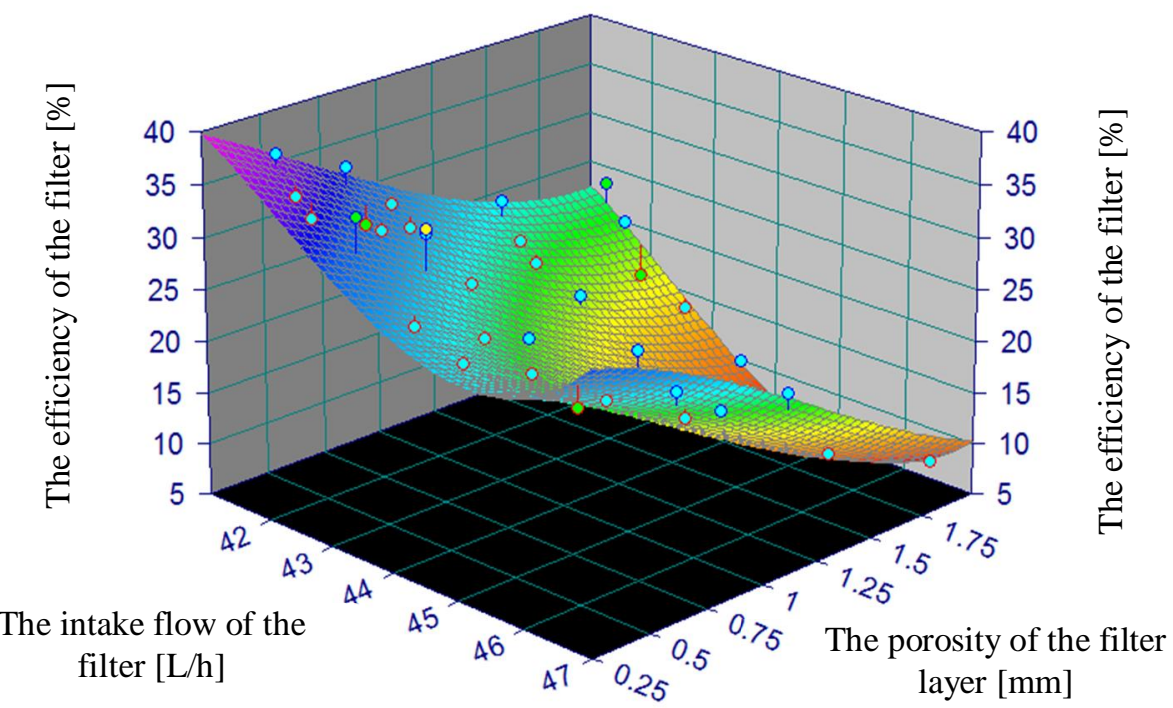

Fig. 3. Tridimensional representations of the filtering process efficiency for the filter with perlite [12]. 


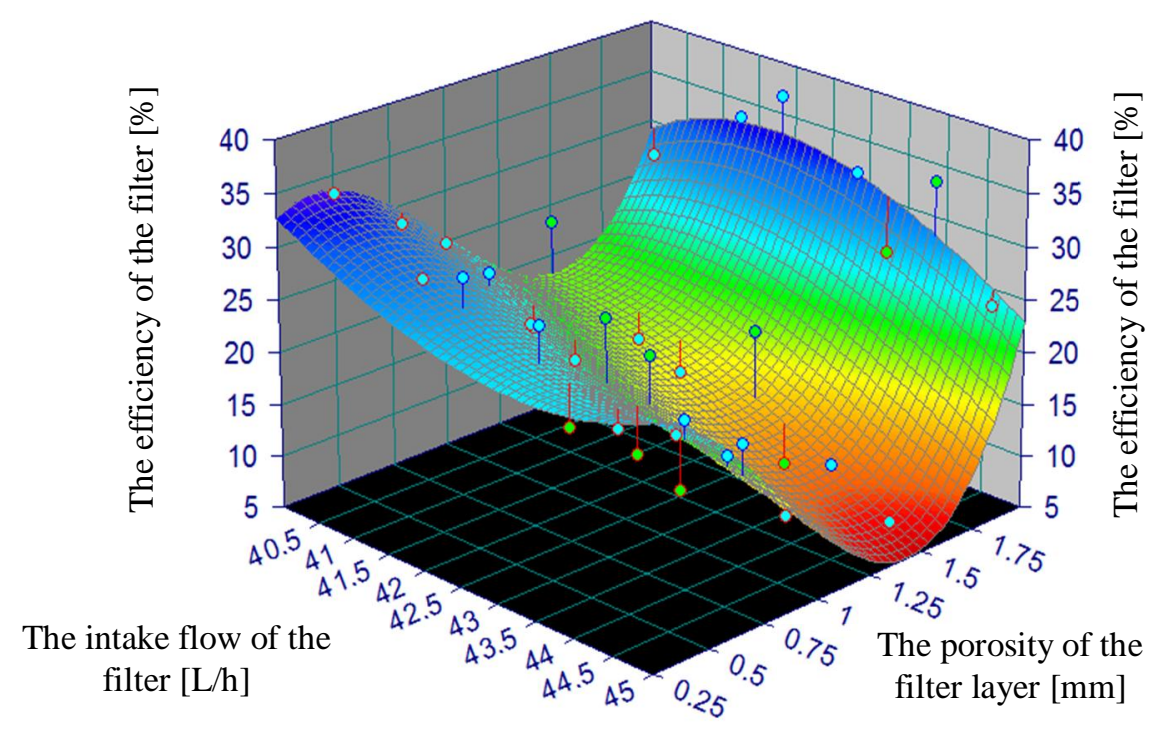

Fig. 4. Tridimensional representations of the filtering process efficiency for the filter with anthracite [12].

\subsection{The verification of mathematical model}

An important direction of the research is functional verification of the mathematical model. The data obtained in the laboratory conditions on efficiency of the water filtration depending upon the porosity of the filter layer, the nature of the filter layer and the intake flow with raw water have helped to verify and validate the mathematical model. Table 4 presents the data obtained experimental comparative with those offered by the software 3D Table Curve and relative deviation of the experimental model to mathematical model [12].

Table 4. The verification of the mathematical model that describes the variation of the filtration efficiency for three types of filter materials depending on the porosity of the filter layer and the intake flow [12].

\begin{tabular}{|c|c|c|c|c|c|c|c|c|}
\hline \multicolumn{3}{|c|}{ Quartz sand } & \multicolumn{3}{|c|}{ Perlite } & \multicolumn{3}{|c|}{ Anthracite } \\
\hline $\begin{array}{c}\text { Experim } \\
\text { ental }\end{array}$ & $\begin{array}{c}\text { Mathematical } \\
\text { model }\end{array}$ & $\begin{array}{l}\text { Relative } \\
\text { deviation }\end{array}$ & $\begin{array}{c}\text { Experim } \\
\text { ental }\end{array}$ & $\begin{array}{c}\text { Mathematical } \\
\text { model }\end{array}$ & $\begin{array}{l}\text { Relative } \\
\text { deviation }\end{array}$ & $\begin{array}{c}\text { Experimen } \\
\text { tal }\end{array}$ & Mathematical model & $\begin{array}{l}\text { Relative } \\
\text { deviation }\end{array}$ \\
\hline 45 & 44.587474 & 0.925205 & 23.33 & 20.6141816 & 13.17451 & 26.66 & 25.54261664 & 4.374585 \\
\hline 50 & 48.594720 & 2.891836 & 25 & 24.8119371 & 0.757953 & 23.33 & 20.6141816 & 13.17451 \\
\hline 51.66 & 54.087313 & -4.48777 & 28.33 & 29.7897541 & -4.90019 & 25 & 24.8119371 & 0.757953 \\
\hline 55 & 57.032592 & -3.56391 & 33.33 & 32.06079763 & 3.958736 & 28.33 & 29.7897541 & -4.90019 \\
\hline 63.33 & 63.056164 & 0.434273 & 36.66 & 35.75627616 & 2.527455 & 33.33 & 32.06079763 & 3.958736 \\
\hline 31.66 & 34.691557 & -8.7386 & 13.33 & 13.48846084 & -1.17479 & 36.66 & 35.75627616 & 2.527455 \\
\hline 33.33 & 39.17 & -14.9308 & 18.33 & 17.89246739 & 2.445345 & 13.33 & 13.48846084 & -1.17479 \\
\hline 40 & 45.3 & -11.798 & 23.33 & 23.16097891 & 0.72 & 18.33 & 17.89246739 & 2.445345 \\
\hline 46.66 & 48.668867 & -4.12762 & 30 & 25.59200318 & 17.22412 & 23.33 & 23.16097891 & 0.729767 \\
\hline 56.66 & 55.478363 & 2.129905 & 33.33 & 29.62444653 & 12.50843 & 30 & 25.59200318 & 17.22412 \\
\hline 35 & 36.358889 & -3.73743 & 15 & 17.11365327 & -12.3507 & 33.33 & 29.62444653 & 12.50843 \\
\hline 40 & 40.771125 & -1.89135 & 20 & 21.40332703 & -6.55658 & 15 & 17.11365327 & -12.3507 \\
\hline 48.33 & 46.83 & 3.193115 & 26.66 & 26.51069554 & 0.563186 & 20 & 21.40332703 & -6.55658 \\
\hline 53.33 & 50.09 & 94 & 28.33 & 28.85 & & 26.66 & 26.9 & 0.563186 \\
\hline 58.33 & 56.77 & 2.731348 & 31.66 & 32.69868736 & -3.17654 & 28.33 & 28.85303641 & -1.81276 \\
\hline 40 & 36.683731 & 9.04016 & 20 & 18.63967718 & 7.297996 & 31.66 & 32.69868736 & -3.17654 \\
\hline 46.66 & 41.080941 & 13.58065 & 21.66 & 22.88757971 & -5.36352 & 20 & 18.63967718 & 7.297996 \\
\hline 50 & 47.123155 & 6.104948 & 26.66 & 27.93607499 & -4.56784 & 21.66 & 22.88757971 & -5.36352 \\
\hline 51.66 & 50.370914 & 2.559185 & 28.33 & 30.24601558 & -6.33477 & 26.66 & 27.93607499 & -4.56784 \\
\hline 58.33 & 57.031593 & 2.276645 & 33.33 & 34.02342236 & -2.03807 & 28.33 & 30.24601558 & -6.33477 \\
\hline 30 & 28.064068 & 6.898258 & 10 & 10.085 & -0.85152 & 33.33 & 34.02342236 & -2.03807 \\
\hline 31.66 & 32.838915 & -3.59 & 15 & 14.63319782 & 2.506644 & 10 & 10.08588333 & -0.85152 \\
\hline
\end{tabular}




\begin{tabular}{|l|c|c|c|c|c|c|c|c|}
\hline \multicolumn{4}{|c|}{ Quartz sand } & \multicolumn{3}{c|}{ Perlite } & \multicolumn{3}{c|}{ Anthracite } \\
\hline $\begin{array}{c}\text { Experim } \\
\text { ental }\end{array}$ & $\begin{array}{c}\text { Mathematical } \\
\text { model }\end{array}$ & $\begin{array}{c}\text { Relative } \\
\text { deviation }\end{array}$ & $\begin{array}{c}\text { Experim } \\
\text { ental }\end{array}$ & $\begin{array}{c}\text { Mathematical } \\
\text { model }\end{array}$ & $\begin{array}{c}\text { Relative } \\
\text { deviation }\end{array}$ & $\begin{array}{c}\text { Experimen } \\
\text { tal }\end{array}$ & Mathematical model & $\begin{array}{c}\text { Relative } \\
\text { deviation }\end{array}$ \\
\hline 40 & 39.413381 & 1.488375 & 20 & 20.10369054 & -0.51578 & 15 & 14.63319782 & 2.506644 \\
\hline 43.33 & 42.954059 & 0.875216 & 21.66 & 22.64587308 & -4.35343 & 20 & 20.10369054 & -0.51578 \\
\hline 50 & 50.231707 & -0.46128 & 25 & 26.91244731 & -7.10618 & 21.66 & 22.64587308 & -4.35343 \\
\hline 33.33 & 32.741394 & 1.797741 & 8.33 & 8.278570399 & 0.621238 & 25 & 26.91244731 & -7.10618 \\
\hline 38.33 & 37.316508 & 2.715932 & 10 & 12.94048503 & -22.7231 & 8.33 & 8.278570399 & 0.621238 \\
\hline 45 & 43.609466 & 3.188604 & 15 & 18.57249759 & -19.2354 & 10 & 12.94048503 & -22.7231 \\
\hline 48.33 & 46.995219 & 2.840247 & 20 & 21.20357091 & -5.67627 & 15 & 18.57249759 & -19.2354 \\
\hline 51.66 & 53.946551 & -4.23855 & 23.33 & 25.65737433 & -9.07098 & 20 & 21.20357091 & -5.67627 \\
\hline 26.66 & 27.006271 & -1.28219 & 6.66 & 7.527223416 & -11.5212 & 23.33 & 25.65737433 & -9.07098 \\
\hline 35 & 31.824778 & 9.977201 & 11.66 & 12.50863601 & -6.7844 & 6.66 & 7.527223416 & -11.5212 \\
\hline 40 & 38.460777 & 4.002059 & 20 & 18.59095565 & 7.579193 & 11.66 & 12.50863601 & -6.7844 \\
\hline 46.66 & 42.035319 & 11.00189 & 23.33 & 21.46985084 & 8.664006 & 20 & 18.59095565 & 7.579193 \\
\hline 48.33 & 49.384295 & -2.13488 & 25 & 26.44563744 & -5.46645 & 23.33 & 21.46985084 & 8.664006 \\
\hline
\end{tabular}

After comparing experimental data with those offered by the mathematical model it is observed that most value of the relative deviations are in range $+5 \%$ and $-5 \%$ (Table 4 and Figure 5). It also notes that the slightest relative deviation of the experimental model compared with mathematical model is $0.43 \%$. This error was recorded when it was determined the filtration efficiency using quartz sand as filter material, the intake flow it was $0.5 \mathrm{~mL} / \mathrm{s}$ and the porosity of the filter layer was $37.66 \%$ [12].

It also observed a high value for relative deviation of the experimental model comparative to mathematical model. This is the $-22.72 \%$, but relative deviations (over $10 \%$ ) are in a small number. In Figure 5 were plotted all values for relative deviations of the mathematical model comparative with experimental model [12].

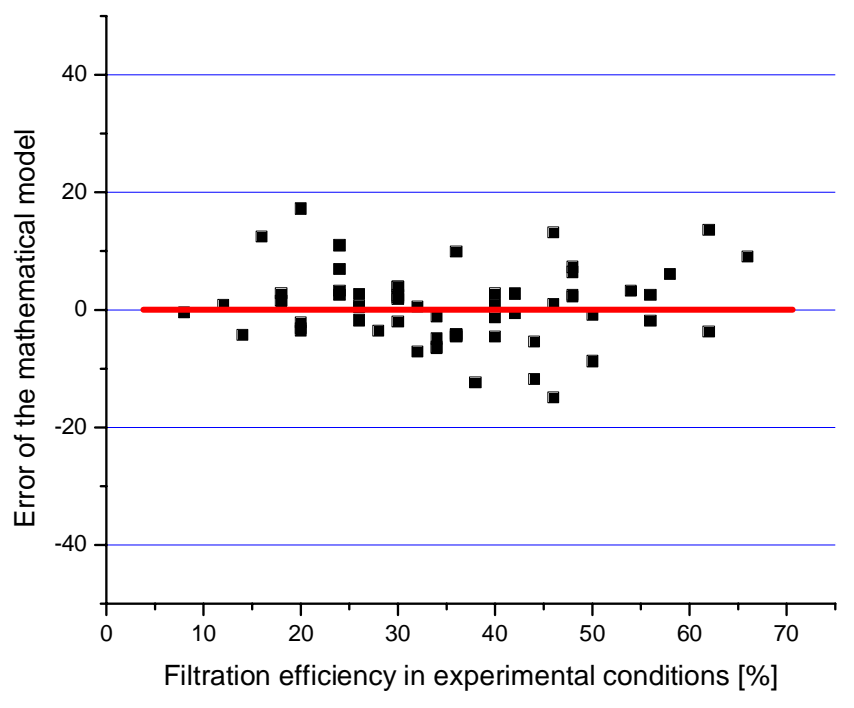

Fig. 5. Graphical representation for the relative deviations of the mathematical model comparative with experimental model [12].

\section{CONCLUSIONS}

Mathematical modeling is an important means for investigating in conditions in which are available experimental data in situ.

Studies have shown that mathematical modeling is a common tool to explain and study the behavior of different processes, thereby avoiding the realization of the experimental measurement, sometimes very laborious and 
expensive. It was also shown that mathematical modeling is an area of great interest in environmental engineering.

The mathematical model developed is based on a series of experimental values obtained under laboratory conditions. It was found that the variable parameters considered for conducting experiments represented the nature of the filter material, the filter porosity and the intake flow of the filter influences the water filtration process.

The mathematical model, validated by comparing experimental data obtained under laboratory conditions to those offered by software for mathematical modeling TableCurve 3D has proved to be an effective one, the relative deviations being in the range of $+5 \%$ and $-5 \%$. It was shown that the mathematical model identified is able to predict the efficiency of filtration process according to the parameters chosen for the experimental study.

\section{REFERENCES}

[1] Bermúdez, A., García-García, L. M., Mathematical modeling in chemistry. Apllication to water quality problems, Applied numerical mathematics, vol. 62, 2012, p. 305 - 327.

[2] Irimia, O., Tomozei, C., Panainte Lehadus, M., A mathematical model on the efficiency of the mechanical water filtering process, Proceedings of the International Multidisciplinary Scientific GeoConference SGEM, vol. 2, 2016, p. $695-702$.

[3] Garira W., Mathebula D., Netshikweta R., A mathematical modelling framework for linked within-host and between-host dynamics for infections with free-living pathogens in the environment, Mathematical biosciences, vol. 256,2014 , p. $58-78$.

[4] Petrescu, V., Sumbasacu, O., Comparison between numerical simulation and measurements of the pollutant dispersion in a river. Case study, U.P.B. Sci. Bull., Series D, vol. 72, no. 3, 2010, p. 157 - 164.

[5] Faridirad, F., Zourmand, Z., Kasiri, N., Kazemi Moghaddam, M., Mohammadi T., Modeling of suspension fouling in nanofiltration, Desalinisation, vol. 346, 2014, p. $80-90$.

[6] Wang, D., Bolton, J.R., Hofmann, R., Medium pressure UV combined with chlorine advanced oxidation for trichloroethylene destruction in a model water, Water research, vol. 46, 2012, p. 4.677 - 4.686.

[7] Yahyapour, S., Golshan, A., Ghazali, A.H., Removal of total suspended solids and turbidity within experimental vegetated channel: optimization through response surface methodology, Journal of hydroenvironment research, vol. 8, 2014, p. $260-269$.

[8] Tirtoaca (Irimia), O., Nedeff, V., Panainte, M., Lazar. G., Potabilizarea apelor. Procedee și tehnici de filtrare, Editura Alma Mater, Bacău, 2014.

[9] Coccagna L., Lasagna C., Granular filter materials, (in Italian), Fondazione AMGA, Genova, 2010.

[10] Tirtoaca (Irimia), O., Tomozei, C., Panainte, M., Mosnegutu, E.F., Barsan, N., Efficiency of filters with different filtering materials: comparative study in water treatment, Environmental engineering and management journal, vol. 12, 2013, p. 5 - 39.

[11] Purchas D., Sutherland K., (2002), Handbook of Filter Media, Elsevier science \& technology books.

[12] Tirtoaca (Irimia), O., Studies and researches on the possibilities to increase the quality of water for different types of uses, Ph.D. Thesis, "Vasile Alecsandri" University of Bacau, Romania, 2011.

[13] TC3D, 2013, Online at: http://www.sigmaplot.com/products/tablecurve3d/tablecurve3d.php (15.02.2015). 